\title{
DEL NEOCLASICISMO AL ECLECTICISMO EN LA ARQUITECTURA GALLEGA. TRES HITOS EN LA OBRA DE FAUSTINO DOMINGUEZ DOMINGUEZ (1817-1890)
}

\author{
por \\ JESUS ANGEL SANCHEZ GARCIA
}

En el todavía mal conocido panorama de la arquitectura gallega en los años centrales del siglo XIX quizás sea especialmente lamentable la escasa atención que hasta ahora ha merecido una de sus figuras más destacadas: el arquitecto Faustino Domínguez Domínguez (1817-1890). Si bien es cierto que en los últimos años ha suscitado referencias en estudios como los de Antonio Meijide, Alfredo Vigo o Xosé Fernández, donde se esboza lo esencial de sus coordenadas biográficas y lo más relevante de su producción', seguimos careciendo de un acercamiento en profundidad a esta compleja personalidad que al margen de su cargo como arquitecto provincial de $\mathrm{La}$ Coruña presenta obra repartida por tres de las cuatro provincias gallegas, con abundantes encargos particulares, y aún unas atinadas reflexiones teóricas sobre la historia y estado de las artes y la arquitectura de su tiempo ${ }^{2}$.

'MEIJIDE PARDO, A. : La Academia y Escuela de Bellas Artes de La Coruña. 1850-1875. Diputación Provincial de La Coruña, 1989 (pp. 52 a 59); VIGO TRASANCOS, A. : «A arquitectura da Ilustración e do século XIX» en $A$ arte galega. Estado da cuestión. Consello da Cultura Galega, La Coruña, 1990 (pp. 330 a 331); y FERNANDEZ FERNANDEZ, X.: Arquitectura del eclecticismo en Galicia (1875-1914). Vol. I. Edificación institucional y religiosa. Universidade da Coruña-Xunta de Galicia, 1995 (pp. 365 a 475).

${ }^{2}$ Esta última faceta debe entenderse en estrecha relación con su vinculación a la Academia coruñesa de Bellas Artes, de la que según Meijide fue el auténtico «alma mater», siendo titular desde su creación y en numerosas ocasiones presidente y secretario. MEIJIDE PARDO, A. : op. cit. (p. 52).

"CUADERNOS De ESTUdIOS GALLEGOS", Tomo XLII, Fascículo 107, Santiago 1995. 
En esta ocasión nuestro propósito es realizar una aproximación parcial al que consideramos uno de los arquitectos más fecundos e influyentes del tercio central del siglo ${ }^{3}$, trazando las líneas generales de su evolución estilística desde el neoclasicismo al eclecticismo. Al margen de los méritos intrínsecos que caracterizan el hacer profesional de Domínguez, su elección obedece a la circunstancia de que en esta trayectoria acompaña fielmente la tendencia de un siglo que iniciado todavía en aquel clasicista lenguaje único asistiría con el tiempo a su crisis y diversificación hasta desembocar en el abanico de las corrientes eclécticas e historicistas.

Sin ánimo de recorrer exhaustivamente la abundante y dispersa producción del arquitecto, ahora nos centraremos en tres proyectos pertenecientes al campo de la arquitectura institucional que pueden servirnos como efectivos jalones a la hora de comprender su evolución arquitectónica. Se trata de unas propuestas pensadas para la ciudad de La Coruña donde ejerció el grueso de su actividad, en las que desde el neoclasicismo tardío plasmado en su proyecto de Universidad (1840), nos encaminaremos hacia las eclécticas formulaciones del Palacio Municipal (1861) y sobre todo el Palacio de la Diputación Provincial (1862), esta última la única de las tres que tuvo la fortuna de construirse según sus planos.

\section{EI proyecto de Universidad para La Coruña (1840).}

Hasta la fecha era muy poco lo que se sabía de los orígenes y formación de Faustino Domínguez Domínguez. Nacido el 15 de Febrero de 1817 en la localidad leonesa de Villamañán, entre León y Benavente, la temprana muerte de sus padres provocó que ya a comienzos de los años 30 se trasladara a La Coruña para residir con su tío el comerciante Isidoro Domínguez Prieto. Bajo su protección inició en 1834 estudios de Aritmética y Geometría en la Escuela de Matemáticas del Real Consulado, dirigida por el arquitecto Alejo Andrade Yáñez, luego continuados con otros de Mecánica y Física en la Universidad de Santiago. Es muy probable que en estos primeros pasos su intención fuera seguir la carrera de ingeniero ya que en 1836 y 1837 aparece matriculado en Madrid en materias como Física Experimental, Química y Mineralogía, estas últimas en el Museo Nacional de Ciencias Naturales ${ }^{4}$.

\footnotetext{
${ }^{3}$ Opinión también compartida por Alfredo Vigo Trasancos: op. cit. (p. 330).

${ }^{4}$ Estos datos inéditos los hemos obtenido a través de la documentación familiar conservada en el archivo de Eduardo García de Dios Domínguez, a quien agradecemos todas las facilidades prestadas para su consulta.
}

"CuAdERNOS DE ESTUdios GALLEGOS", Tomo XLII, Fascículo 107, Santiago 1995. 
Sin embargo, también en 1836 sería admitido como discípulo de la Academia de San Fernando, institución en la que definitivamente encauzaría sus estudios hacia la arquitectura. Cuatro años después, en su solititud para optar al examen de arquitecto hacía constar que en La Coruña había efectuado su aprendizaje sobre dicha materia en contacto con dos arquitectos de la generación anterior: el citado Alejo Andrade Yáñez y José María Noya Vaamonde. El primero (Monforte de Lemos, 1792-18??) era arquitecto desde 1818, título ampliado con el de académico de mérito en 1822 , y es seguro que al menos desde 1834 se encontraba trabajando en La Coruña como lo corrobora una de sus obras más conocidas, la capilla del cementerio que responde precisamente a esa fecha ${ }^{5}$; en cuanto a José María Noya (La Coruña, 1798-1868), titulado en 1832, ejercía desde 1834 el cargo de arquitecto municipal, siendo el proyecto para el Teatro Principal (1838) su obra más destacada aunque quedara inconclusa por problemas económi$\cos ^{6}$.

Al margen del contacto con estos arquitectos gallegos, Domínguez finalizaría sus estudios en la Corte bajo la dirección de Luis de Olarrieta. De los personajes y contexto que acompañaron su formación nos interesa destacar la nota común de su adscripción a la última generación de la corriente neoclásica, con lo que ya nos situaríamos en la fase epigonal del estilo, la de los primeros años del reinado de Isabel II (1833-1843). En este período está constatado a nivel de toda España que la prolongación de tal tendencia implicará su debilitamiento progresivo hasta finalmente dar como últimos frutos unas construcciones donde la puntual orquestación de elementos

\footnotetext{
${ }^{5}$ Archivo de la Real Academia de Bellas Artes de San Fernando. Actas Sección de Arquitectura. Libro 1806 a 1823, Juntas del 10-XI-1818 y 7-IX-1822 (fols. 148 y 217). También PARRILLA HERMIDA, M. : «Una página de la historia sanitaria de La Coruña. La epidemia de 1809 y el primer cementerio general de la ciudad» en Revista del Instituto José Cornide, Núm. 6-7, 1969-1970 (pp. 153 a 171); y NAVASCUES PALACIO, P. : La arquitectura gallega del siglo XIX. COAG, Santiago de Compostela, 1984 (pp. 8 a 13).

${ }^{6}$ A.R.A.B.A.S.F. Actas Sección de Arquitectura. Libro 1832 a 1840. Junta del 11 IX-1832 (fol. 34). También NAYA PEREZ, J. : Noticia histórica de las galerías coruñesas y relación de arquitectos de La Coruña... Instituto José Cornide de Estudios Coruñeses, La Coruña, 1965 (pp. 68 y 69); MEIJIDE PARDO, A. : op cit. (p. 66); VIGO TRASANCOS, A. : op. cit. (pp. 329 y 330); y SANCHEZ GARCIA, J. A. : «José María Noya y el proyecto para el Teatro Principal - Rosalía de Castro - de La Coruña (1838)» en Revista del Instituto José Cornide, Núm. 27-28, 1992-93 (pp. 245 a 270).
}

"CUADERNOS DE ESTUDIOS GALLEGOS", Tomo XLII, Fascículo 107, Santiago 1995. 
clasicistas ya no será suficiente como para definir un carácter global neoclásico?.

Con este bagaje formativo ya hemos anticipado que Domínguez solicitaría en Diciembre de 1840 su admisión a los ejercicios de prueba y examen para el título de arquitecto por la Real Academia. Para ello presentó los diseños de una Universidad para La Coruña, de los que a continuación nos ocupamos, acompañados de su informe facultativo y cálculo detallado ${ }^{8}$. El proyecto, recogido en cuatro planos, ofrece una gran complejidad tanto por la dificultad del programa elegido como por sus dimensiones. Ciertamente con él Domínguez estaba evidenciando una madurez impropia de su edad 23 años -, circunstancia que se ve además confirmada si tenemos en cuenta que ya seis meses antes habían sido entregados en la Academia unos planos de su autoría con vistas a la construcción del Teatro Principal de Santiago.

Lo que Domínguez plantea como Universidad es un descomunal edificio destinado a contener todas las enseñanzas superiores tradicionales, tanto científicas como filosóficas, literarias o religiosas, además de otras de nuevo cuño como la Economía Política, establecida en la reglamentación de 1836 y aún sin implantar en la vecina Universidad de Santiago. A pesar de estar concebido para La Coruña su carácter de prueba de examen lo convierte en una propuesta ideal y por ello sin ningún tipo de limitación espacial o presupuestaria. No obstante, en relación al contexto de la época no se trata de un proyecto tan utópico si tenemos en cuenta el ascenso en el

\footnotetext{
${ }^{7}$ En esta periodización seguimos la establecida en NAVASCUES PALACIO, P. : «Arquitectura española (1808-1914)» en Summa Artis. Historia General del Arte, Tomo XXXV. Espasa-Calpe, Madrid, 1993 (pp. 180 a 212).

${ }^{8}$ A.R.A.B.A.S.F. Actas Sección de Arquitectura. Libro 1832 a 1840. Junta del 15XII-1840 (fols. 238 y 239). En cuanto a la localización del proyecto: Gabinete de Dibujos. A. 669 a 672 .

${ }^{9}$ Estos planos fueron presentados obviamente por un arquitecto ya titulado como era Manuel de Prado y Vallo, al que paradójicamente solo se le había encargado la dirección de las obras. Así se puede confirmar según el acta académica donde consta que «Manuel de Prado y Vallo presenta los diseños de un proyecto de teatro que varios particulares tratan de construir en Santiago... y que dice le fueron entregados al encargarle la obra con el pliego de condiciones que firma su autor D. Faustino Domínguez». Idem, idem. Junta del 16-VI-1840 (fols. 225 a 226). Situación ya apuntada por SORALUCE BLOND, J. R. : «El espacio del espectáculo. Los primeros teatros de Galicia» en Boletín Académico de la ETSA de La Coruña, N ${ }^{\circ}$ 9, 1988-2 (p. 32); y SANCHEZ GARCIA, J. A. : La arquitectura teatral en Santiago de Compostela (17681946). Ediciós do Castro, Sada-A Coruña, 1993 (pp. 86 a 88).
}

"CUADERNOS DE ESTUdIOS GALlEGOS", Tomo XLII, Fascículo 107, Santiago 1995. 
número de alumnos matriculados en la universidad compostelana que conoció Domínguez, especialmente en los años 1836 a 1842, y de otra parte la coyuntura de crisis con restricciones y supresiones de centros que la estaban afectando desde la instauración del régimen liberal, lo cual no hacía tan descabellado soñar, especialmente en los momentos de hegemonía política del partido progresista, en la constitución de una segunda universidad en una ciudad más afecta a la causa liberal y pujante como La Coru$\tilde{n} a^{10}$.

En su disposición general la Universidad proyectada adopta una planta rectangular con la fachada principal extendida a lo largo de un lado mayor de unas dimensiones de casi 600 pies de largo (166 mts.). El esquema compositivo de esa fachada es de clara raíz palaciega al dividirse en un cuerpo bajo en sillería almohadillada sobre el que se sitúa el nivel principal, con dos hileras de ventanas y sin ático (Fig. 1). Ordenando y jerarquizando ese frente de amplia extensión horizontal se disponen tres pórticos de columnas jónicas exentas, hexástilo el central y tetrástilos los laterales. Cada uno de esos pórticos y su resalte con respecto a la línea de fachada sirven para marcar el eje central de las tres partes en que se subdividiría la misma; ahora bien, en cada uno de los flancos se reitera esa distribución tripartita general al acompañarse cada pórtico tetrástilo de dos cuerpos apenas salientes. Con ello el señalado desarrollo en horizontal apenas es compensado por los remates de los distintos pórticos, con entablamentos y acróteros grupos escultóricos, lo que recarga y hace más pesada la apariencia general del edificio.

A la hora de buscar un posible modelo para esta fachada es evidente el parentesco con una construcción cortesana de primer nivel como el Palacio Real de Madrid, con el que comparte la diferenciación de pisos, esquema tripartito y aún los mismos tipos de vanos, si bien depurando la ornamenta-

${ }^{10}$ Sobre la situación de la universidad compostelana en esta fase del siglo XIX véase: VARELA GONZALEZ, I. : «Universidad» en Gran Enciclopedia Gallega. Tomo 29, Suárez-Vaz. Silverio Cañada ed., Santiago, 1974-1976 (pp. 187 a 190); IDEM : "Aspectos de la Universidad en el Período Isabelino (1833-1868» en La Universidad de Santiago (DIAZ Y DIAZ, M. Coord.). Santiago de Compostela, 1980 (pp. 67 a 75).

En cuanto al progresivo despegue demográfico y económico de La Coruña a partir de los años 30 hasta alcanzar los 27.000 habs. en 1857, en contraste con el estancamiento de Santiago, hasta entonces primera ciudad de Galicia: BARREIRO FERNANDEZ, X. R. : Historia de la Ciudad de La Coruña. Biblioteca Gallega, La Coruña, 1986 (pp. 279 y 280 ).

"CUADERNOS DE ESTUDIOS GALLEGOS", Tomo XLII, Fascículo 107, Santiago 1995. 


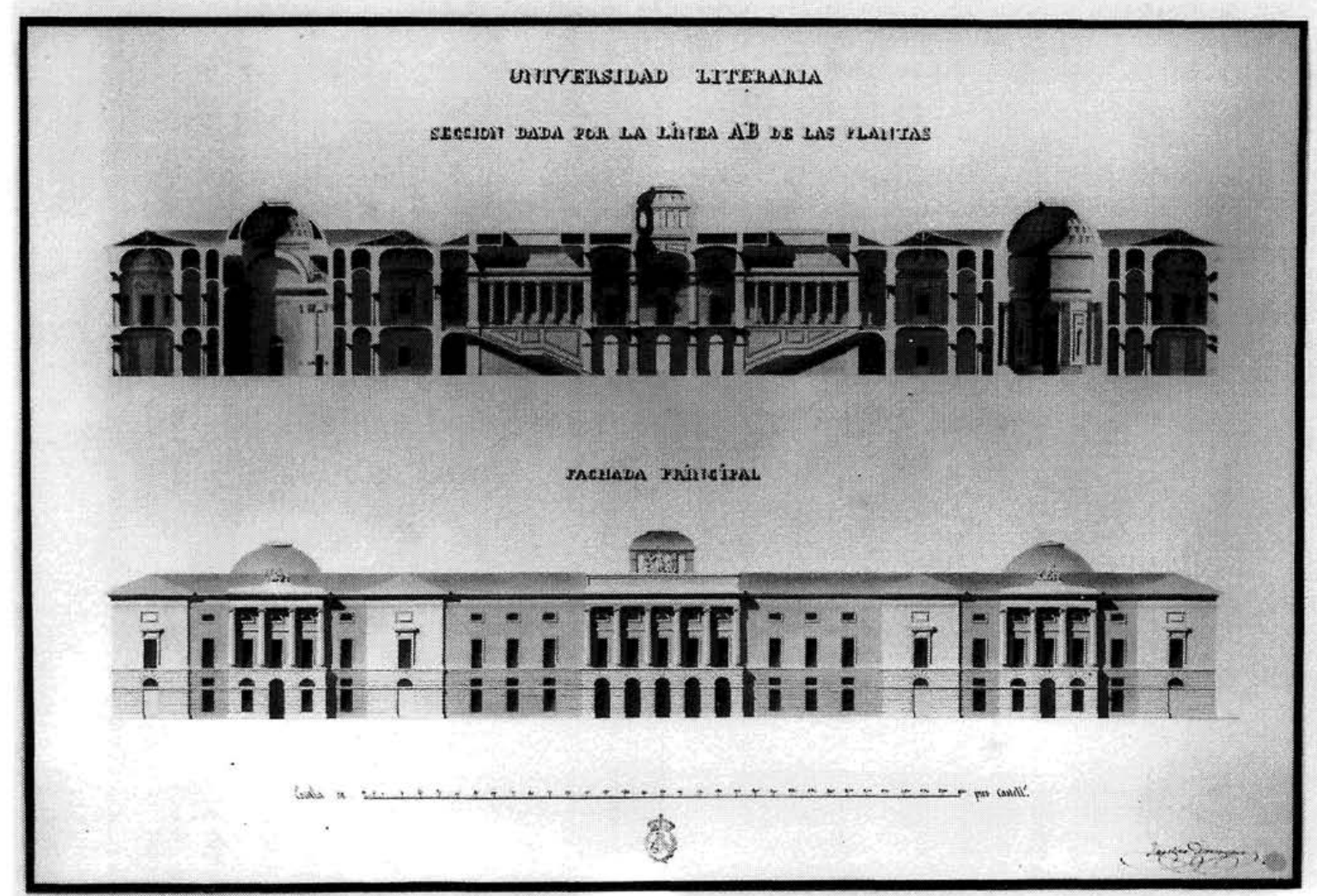

Figura 1. Proyecto de Universidad para La Coruña (Faustino Domínguez, 1840). Sección y fachada principal. 


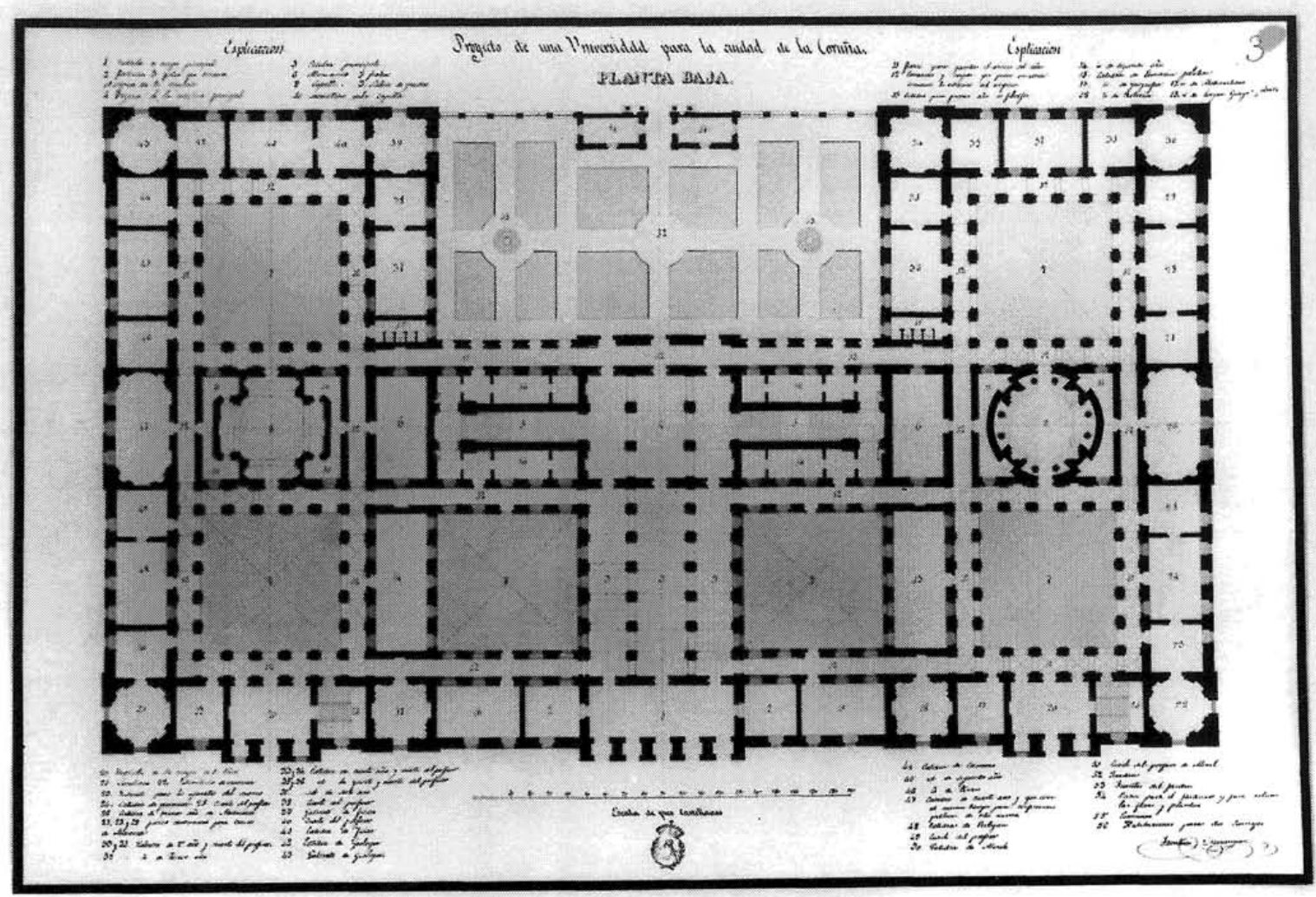

Figura 2. Proyecto de Universidad para La Coruña (F.D., 1840). Planta baja. 
ción y elementos arquitectónicos añadidos a los tramos parietales --pilastras adosadas, balaustrada superior-. De acuerdo con esta inspiración nos encontramos con un edificio universitario que en lugar de acudir a la metáfora del «Templo del Saber» presente en la universidad compostelana proyectada a finales del siglo XVIII por Ferro Caaveiro, es resuelto como Palacio, a pesar de mantener como remate del cuerpo central casi idéntico grupo escultórico presidido por Atenea. Por esta razón el alzado de este proyecto empieza a marcar ya una distancia con la dogmática neoclásica, en especial con su abandono de la rígida solución del frente templario - - pórtico de columnas y frontón-, evidenciando un modo de hacer progresivamente más libre en relación a la producción del primer tercio de la centuria y no dudando en retomar fórmulas del clasicismo barroco italiano.

Las referencias palaciegas continúan en el interior puesto que el recorrido principal, tras rebasar el pórtico central de acceso, discurre por un vestíbulo y una amplia galería que desemboca en el núcleo del conjunto, ocupado por el espacio desde el que arrancan las dos regias escaleras de tiros enfrentados que conducen a la planta principal (Fig. 2). Sin embargo, sin salir de esa planta baja, desde ese espacio central se genera el segundo eje vertebrador del edificio puesto que en la dirección que marcan las escaleras y permiten recorrer dos pares de corredores se accede a los dos espacios centralizados en torno a los que se organizan los flancos del edificio. Se trata de la rotonda columnaria del salón de grados situada a la derecha y a la izquierda la cruz griega de la capilla, encerradas en sus respectivas crujías y rodeadas por unas piezas en los ángulos para sacristía y habitaciones de servicio.

En función de ese cruce de ejes con forma de $\mathrm{T}$ acortada se entiende mejor la ubicación de la serie de patios alrededor de los cuales se disponen las cátedras para las distintas enseñanzas. Estos patios son cuatro hacia el cuerpo de fachada y sólo dos hacia la parte trasera por estar ocupada la zona central por un jardín con dos fuentes (Fig. 3). Con ellos se está retomando el tradicional esquema claustral como fórmula más idónea de resolver la circulación de los alumnos hacia las correspondientes cátedras, situándose en planta baja las de Filosofía, Economía Política, Geografía, Matemáticas, Retórica, Griego y Arabe, Química, Medicina, Física, Geología, Cánones, Religión y Moral, mientras que en la superior se alojarían las de Historia Moderna, Historia Antigua, Mineralogía, Ideología, Derecho Político, Dialéctica, Teología, Historia Eclesiástica, Leyes, Literatura Española, Literatura Extranjera, Elocuencia Forense y Poesía. Acompañando las aulas se abren también cuartos de profesores, gabinetes de apa- 


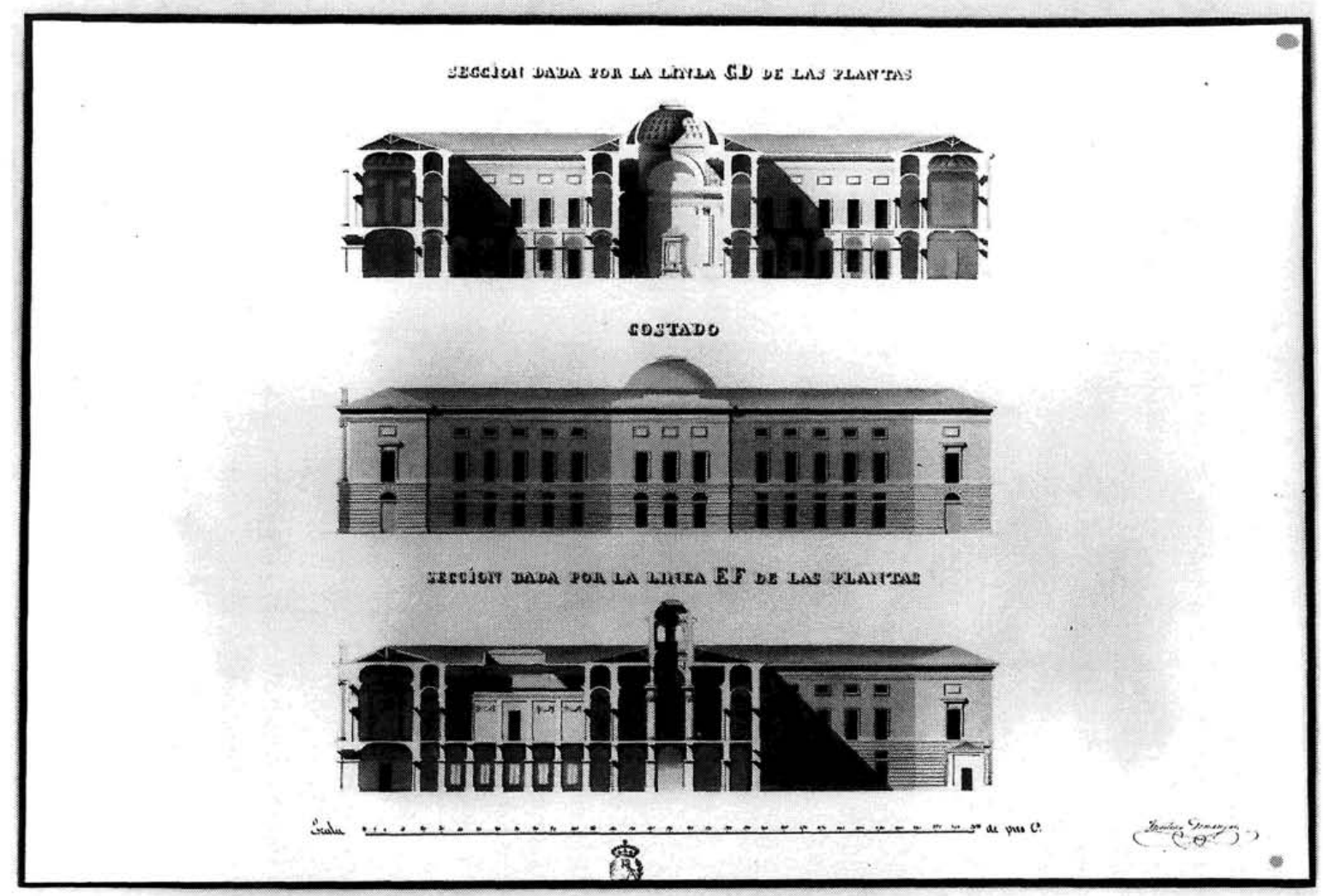

Figura 3. Proyecto de Universidad para La Coruña (F.D., 1840). Secciones y costado. 
ratos o un Museo de Medicina en la planta baja, completados en la alta por locales para archivo, museo de antiguedades, secretaría, tesorería y, sobre todo, una Biblioteca que ocupa prácticamente el ala Oeste de ese nivel ${ }^{11}$.

Salvando cierto paralelismo del citado eje vertebrador con el ritmo de espacios presente en la sección del Museo del Prado de Villanueva, para la interpretación del proyecto de Domínguez como conjunto es obligado acudir a un modelo de referencia más manejable por los arquitectos en formación de su generación. Sin duda fue la obra teórica de Jean-Nicolas-Louis Durand, en concreto su Précis des leçons d'architecture données à l'Ecole Royale Polytechnique (1802-1805). De hecho sólo a la luz de esta obra puede entenderse el tipo de composición aditiva que despliega Domínguez, presidida en todo momento por los principios de simetría, regularidad y simplicidad recomendados por Durand ${ }^{12}$.

Como ejercicio de diseño este proyecto encarnaría a la perfección el método de trabajo expuesto por el maestro francés puesto que analizando cualquiera de las plantas es fácil descubrir los ejes paralelos y perpendiculares a partir de los cuales se han ido disponiendo las distintas partes arquitectónicas - vestíbulos, aulas, galerías, corredores--, siempre con formas regulares y reductibles en último término a un módulo único. Por ello desde esos presupuestos se hace inteligible la trama ortogonal que gobierna toda la planta, presidida por los dos ejes axiales, así como la serie repetida de patios que suministran por subdivisión las dimensiones del resto de espacios que los rodean. Ahora bien, no sólo se recogen en el proyecto esos principios generales del diseño estandarizado sino que partes concretas del mismo están inspiradas en las láminas del Précis: como pudieran ser las escaleras principales enfrentadas o las aulas y gabinetes de variadas formas concatenados en torno a cada patio (Fig. 4).

Para finalizar, los elementos arquitectónicos que aparecen en los alzados - columnas jónicas y corintias, pilastras, arcos de medio punto, cúpulas y bóvedas casetonadas- constituyen la referencia más clara al universo neoclásico que, aún vigente, estaba por entonces en proceso de disolu-

\footnotetext{
${ }^{11}$ En esta ubicación puede encontrarse una concomitancia con la disposición del gran salón de lectura de la universidad compostelana.

${ }^{12}$ En relación a estos aspectos de la teoría arquitectónica de Durand véanse: SZAMBIEN, W. :J.-N.-L. Durand. 1760-1834. De l'imitation á la norme. Picard, Paris, 1984 (pp. 80 a 92); y VILLARI, S. : J.-N.-L. Durand (1760-1834). Arte e scienza dell'architettura. Officina Edizioni, Roma, 1987 (pp. 86 a 97).
}

"CUADERNOS DE ESTUdiOS GALlEGOS", Tomo XLII, Fascículo 107, Santiago 1995. 
ción. En este aspecto la arquitectura de Silvestre Pérez que tanta influencia había tenido en la obra de sus maestros Alejo Andrade y José María Noya apenas deja traslucir un eco muy atenuado, como la relación de los pórticos externos con obras como la Casa Consistorial de San Sebastián (1823). De hecho Domínguez conscientemente mesura la dimensión monumental de su proyecto y la somete a las exigencias modernas de utilidad y racionalidad que en adelante serán claves en su arquitectura.

\section{Los proyectos para la Casa Consistorial (1861) y el Palacio de la Diputación Provincial (1862)}

Una vez en posesión del título de arquitecto Faustino Domínguez se instalará definitivamente en La Coruña, contrayendo matrimonio en 1843 con María Luisa Coumes-Gay Pulleyro, de origen francés, con la que tendrá dos hijos: Faustino y José, el primero arquitecto y el segundo delineante ${ }^{13}$. En estos primeros años de actividad son escasas las obras en las que consta su intervención, ya que no será más que a partir del año 1846 cuando tenga lugar su verdadero despegue profesional. En esta fecha proyecta y dirige las obras de la Aduana de La Coruña y ocupa la plaza de arquitecto provincial, siendo el primer facultativo de esta institución. Desde este puesto en adelante se encargará de proyectar toda una serie de edificios administrativos, asistenciales, educativos y judiciales fruto de la reorganización estatal impulsada por la burguesía en el poder, entre los que destacarán las numerosas cárceles de partido diseminadas por buena parte de la geografía gallega. Así, en 1849 proyectó el edificio para ayuntamiento, audiencia y cárcel de Vivero, en 1850 la cárcel de Tuy, en 1852 las de Noya y Becerreá, en 1853 las de Ortigueira - construida en 1856 -, Muros, Arzúa, Betanzos y nuevamente la de Vivero, y en 1854 las de Ribadeo - concluida en 1857 y Quiroga ${ }^{14}$.

En 1857 Domínguez solicitará su nombramiento oficial como Director de Obras Públicas de la Provincia y Arquitecto Provincial, alegando los 11 años de servicios prestados, con los proyectos reseñados, así como su autoría y dirección de obra en las cárceles entonces en construcción en Puentedeume,

${ }^{13}$ MEIJIDE PARDO, A. : op. cit. (p. 52). Si el primero en su corta carrera será una de las figuras más destacadas de nuestra arquitectura ecléctica, el segundo auxiliará las tareas de su progenitor como segundo delineante de la Diputación desde 1862.

${ }^{14}$ Todos estos proyectos fueron sometidos a la preceptiva censura de la Academia de San Fernando, mereciendo la aprobación general con algunas observaciones puntuales.

"CUADERNOS DE ESTUDIOS GALLEGOS", Tomo XLII, Fascículo 107, Santiago 1995. 


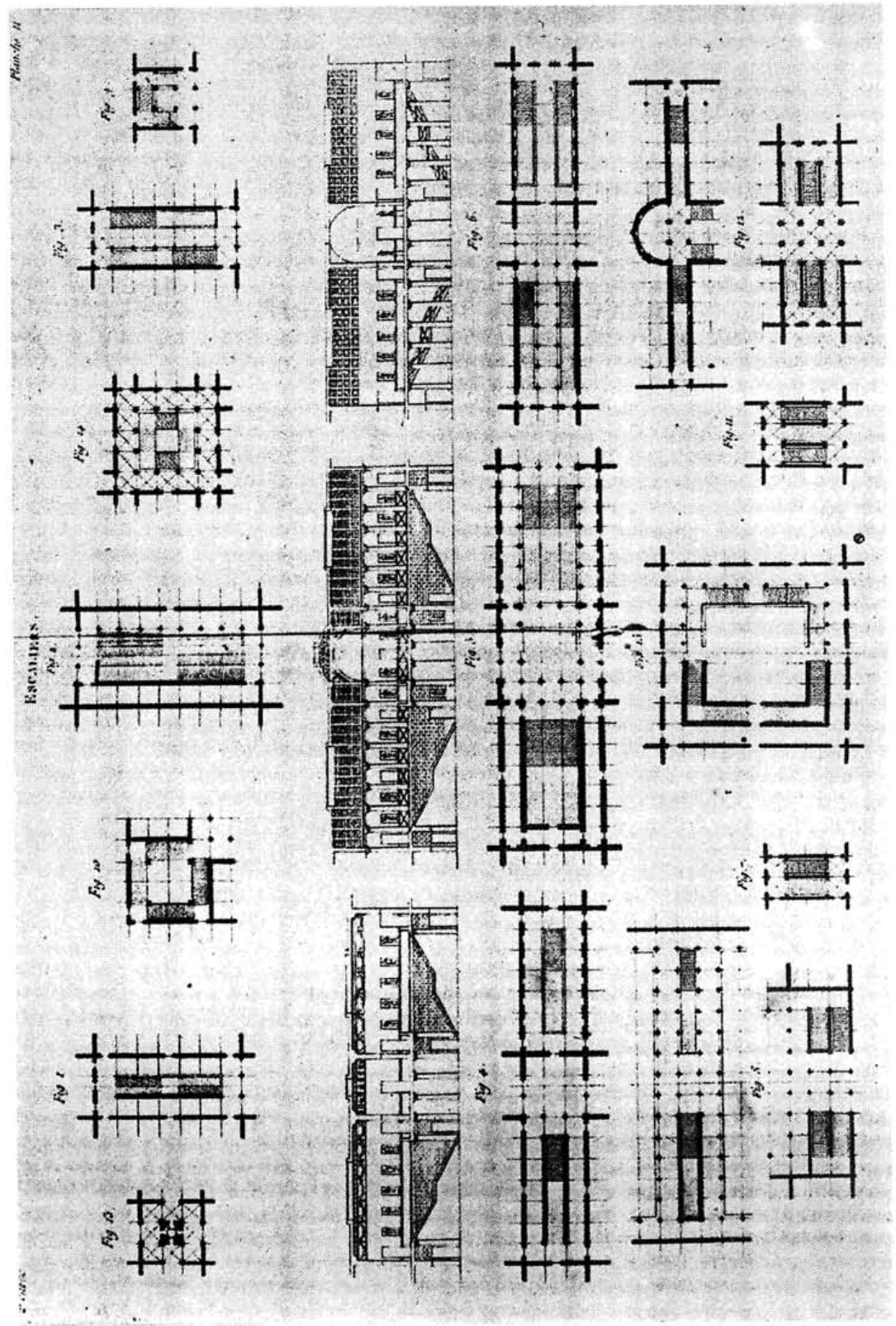




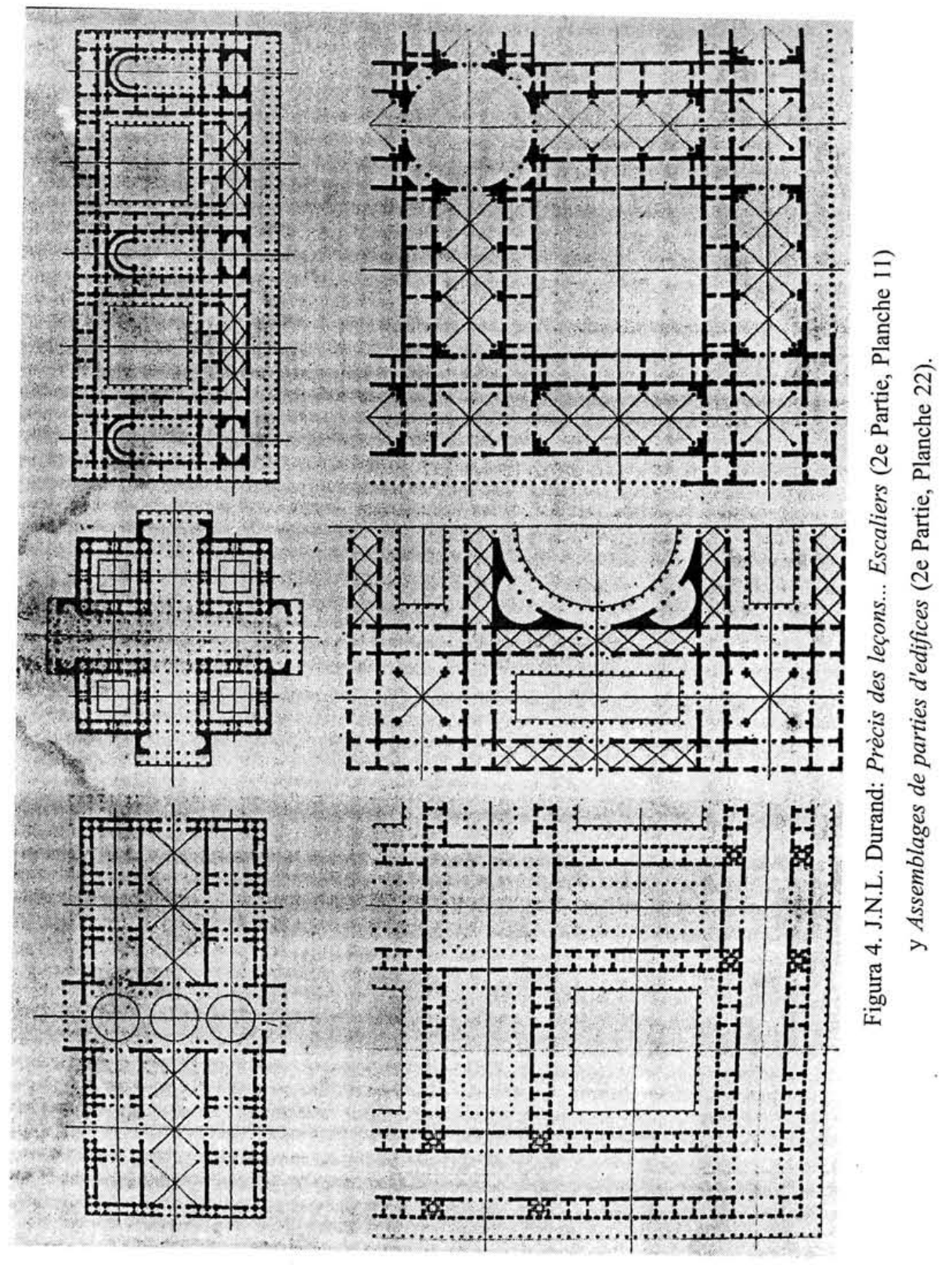


Carballo, Negreira y Corcubión. Desde el Ministerio de la Gobernación se le reconocerían sus «conocimientos relevantes en la profesión, acrisolada probidad, y un celo recomendable por el servicio público», lo que llevaría a que por Real Orden del 26 de Enero de 1859 se le nombrara Arquitecto interino de la Provincia, cargo que obtendrá definitivamente desde el 18 de Junio de ese mismo año ${ }^{15}$.

En lo que respecta al plano estilístico, esos años de actividad supondrán para Domínguez una progresiva depuración y revisión de su clasicismo, opción a la que sin embargo siempre se mantendrá fiel. Dada la escasa relevancia de sus construcciones institucionales, en buena medida debido a la mala coyuntura del país, será más importante su trayectoria a nivel teórico al aceptar la crisis del estilo único de su formación, en lo que será el primer estadio en su evolución hacia el eclecticismo. Por ejemplo, ya en el discurso leído en 1850 en el acto de instalación de las cátedras de la Academia de Bellas Artes de La Coruña demostrará su percepción de las transformaciones de los últimos años al constatar como en la arquitectura de «la época actual en que tantos medios puestos en acción facilitan el estudio, se nota una tendencia general hacia todos los estilos que habian sido olvidados desde la restauración $\rangle^{16}$. De este texto puede extraerse que un atento Domínguez era consciente del cambio producido con la reorganización desde 1846 de la Academia de San Fernando y los nuevos estudios impartidos en la recién creada Escuela Especial de Arquitectura, aspectos claves para entender la génesis del eclecticismo en nuestro país por coadyuvar a la creciente sensibilidad hacia el estudio y recuperación de la arquitectura del pasado ${ }^{17}$. A la hora de explicar este posicionamiento parece probable que Domínguez recibiera una revista como el Boletín Español de Arquitectura que, como ha señalado Angel Isac, también desde 1846 con su

\footnotetext{
${ }^{15}$ Archivo General de la Administración. Ministerio de Educación. Subsecretaría. Personal. 9637-84, Caja A-C.

${ }^{16}$ DOMINGUEZ, F. : Discurso que leyó el día 29 de Setiembre de 1850 en el acto de la instalación de las cátedras de la Academia de Bellas Artes de La Coruña. Imp., Lib. y Tip. de Puga, Coruña, 1850 (p. 29).

${ }^{17}$ Por ello el espíritu de este escrito marcaría un claro precedente con respecto a textos posteriores del mismo autor donde ya es total la aceptación de las corrientes historicistas, como los de 1861 y 1866 aportados por FERNANDEZ FERNANDEZ, X.: op. cit. (p. 19)
}

"CUADERNOS DE ESTUDIOS GALLEGOS", Tomo XLII, Fascículo 107, Santiago 1995. 
teorización del eclecticismo estaba provocando la reflexión de aquellos arquitectos formados como él en la tradición vitruviana ${ }^{18}$.

Cinco años más tarde, comisionado para visitar la Exposición Universal de París por encargo de la Diputación Provincial tendrá ocasión de contemplar «in situ» las primeras realizaciones eclécticas del II Imperio Francés, convirtiéndose en espectador privilegiado de obras como las nuevas alas del Louvre o el mismo Palacio de la Industria. A la vez los proyectos y obras presentados por otras naciones, en especial las neogóticas inglesas, le permitirán ya comprender sin dudas que la falta de estilo era la nota distintiva de la época, puesto que «No hacemos más que copiar hoy lo que hicieron ayer los que nos precedieron, y se ha apoderado de los arquitectos un deseo voraz de estudiar y de reproducir cuanto se ha ejecutado en todos los estilos ${ }^{19}$.

Tras estas primeras experiencias personales de las corrientes eclécticas e historicistas habrá que esperar hasta el año 1861 para encontrar un reflejo concreto en su actividad arquitectónica. Se tratará en esta ocasión del proyecto para la Casa Consistorial de la ciudad, obra anhelada desde finales del siglo XVIII y encargada por el Ayuntamiento el 20 de Marzo de 1860 una vez aprobado el plano elaborado conjuntamente por Domínguez

\footnotetext{
${ }^{18}$ Considérese por ejemplo la significativa publicación en sus páginas del discurso pronunciado por Aníbal Alvarez en la Escuela Especial al inaugurar la enseñanza de la Historia de la Arquitectura, donde optaba por no dar preferencia a ningún género de arquitectura. ISAC, A.: Eclecticismo y pensamiento arquitectónico en España. Discursos, revistas, congresos 1846-1919. Diputación Provincial de Granada, 1987 (pp. 145 y 146); y NAVASCUES PALACIO, P. : «Arquitectura española (1808-1914)»... (pp. 40 y $41)$.

${ }^{19} \mathrm{El}$ matiz negativo de estas palabras se deriva sin duda del desconcierto de nuestro arquitecto al comparar allí reunidos los estilos "greco-romano» de la catedral de San Pablo con el «ojival» del Parlamento de Londres, el «renacimiento» del citado Palacio de la Industria o el «griego» del Templo de la Magdalena. A modo de explicación aventura que se trataría de una situación transicional ya que: «Hay en la sociedad moderna una ansiedad profunda y una inquietud constante; se siente vagamente un deseo y una necesidad de llegar a un nuevo orden, lo mismo en las cosas que en las ideas: este estado de suyo violento, no deja tiempo para las grandes creaciones de la arquitectura, y sólo así puede esplicarse la falta de un nuevo estilo para caracterizar la época». DOMINGUEZ, F. : Informe sobre la Esposición Universal de París dedicado a la Escelentísima Diputación Provincial de La Coruña. Imp. de D. Domingo Puga, Coruña, 1855 (p. 77). Con ello muestra también su puesta al día en la aceptación general del eclecticismo como un fenómeno de transición a la espera del nacimiento del estilo original y propio del siglo XIX. ISAC, A. : op. cit. (p. 34).
}

"CUADERNOS DE ESTUdiOS GALlEGOS", Tomo XLII, Fascículo 107, Santiago 1995. 
y José María Noya para la ordenación de la futura plaza de María Pita ${ }^{20}$. La principal razón para dejar este importante proyecto en manos de Domínguez estribará en que también había trazado con éxito la uniforme solución para las fachadas de las casas que debían cerrar la plaza, con lo cual sólo él podía asegurar que el conjunto fuera concluido con total uniformidad ${ }^{21}$.

Pese al tiempo transcurrido desde aquella propuesta para la Universidad este proyecto vuelve a solucionarse con una planta rectangular en la que la parte posterior se abre en un retranqueo central (Fig. 5). En esta ocasión no es, sin embargo, una opción libre del arquitecto sino que la proyectada construcción a espaldas del futuro ayuntamiento de un pabellón para oficiales e ingenieros militares estaba condicionando y limitando el fondo que se podría alcanzar. Por lo demás el esquema organizativo retoma también, aunque muy simplificado y a menor escala, el planteado en el proyecto de Universidad puesto que tras el pórtico principal se encuentra un espacio de recepción o vestíbulo desde el que se accedería a las dos escaleras principales, ahora situadas en paralelo para aprovechar al máximo el escaso espacio disponible en fondo ${ }^{22}$.

A los lados de ese núcleo dos patios rodeados de una galería perimetral vuelven a ser el recurso para organizar las distintas dependencias, situándose en planta baja un salón para quintas y elecciones, con un cuarto anexo para reconocimientos médicos, un almacén de herramientas, el local de la

${ }^{20}$ A.M.C. Libros de Actas Municipales, año 1860. Sesión del 20 de Marzo (folios 30 y 31$)$.

${ }^{21}$ La comunicación a Domínguez de tal encargo insistía en que se hacía «para que en toda la decoración de la referida plaza haya una cabal uniformidad en el pensamiento y en el especial gusto que nace de la inspiración particular del facultativo». A.M.C. Obras Municipales. C-1013. «Exp. relativo al proyecto de edificación de una nueva Casa Consistorial en el término denominado «Derribo de murallas» existente entre las dos poblaciones alta y Pescadería de esta ciudad». Año de 1860.

Al mismo proyecto se han referido publicando sus planos Arturo Franco Taboada y Xosé Fernández, este último explicando como un anterior proyecto de Domínguez, ganador del concurso convocado en 1858 pero luego desechado, la mala salud de Noya y la necesidad de alojar las dependencias provinciales decidieron también a las autoridades a la hora de adjudicarle el encargo. FRANCO TABOADA, A. : «La plaza de María Pita» en Revista Abrente, N ${ }^{\circ}$ 16-18, 1984-986 (pp. 91 a 106); FERNANDEZ FERNANDEZ, X. : op. cit. (pp. 83 a 97).

${ }^{22}$ Con esta disposición desaparece además aquel eje transversal y su secuencia espacial.

"CUADERNOS DE ESTUDIOS GALLEGOS", Tomo XLII, Fascículo 107, Santiago 1995. 


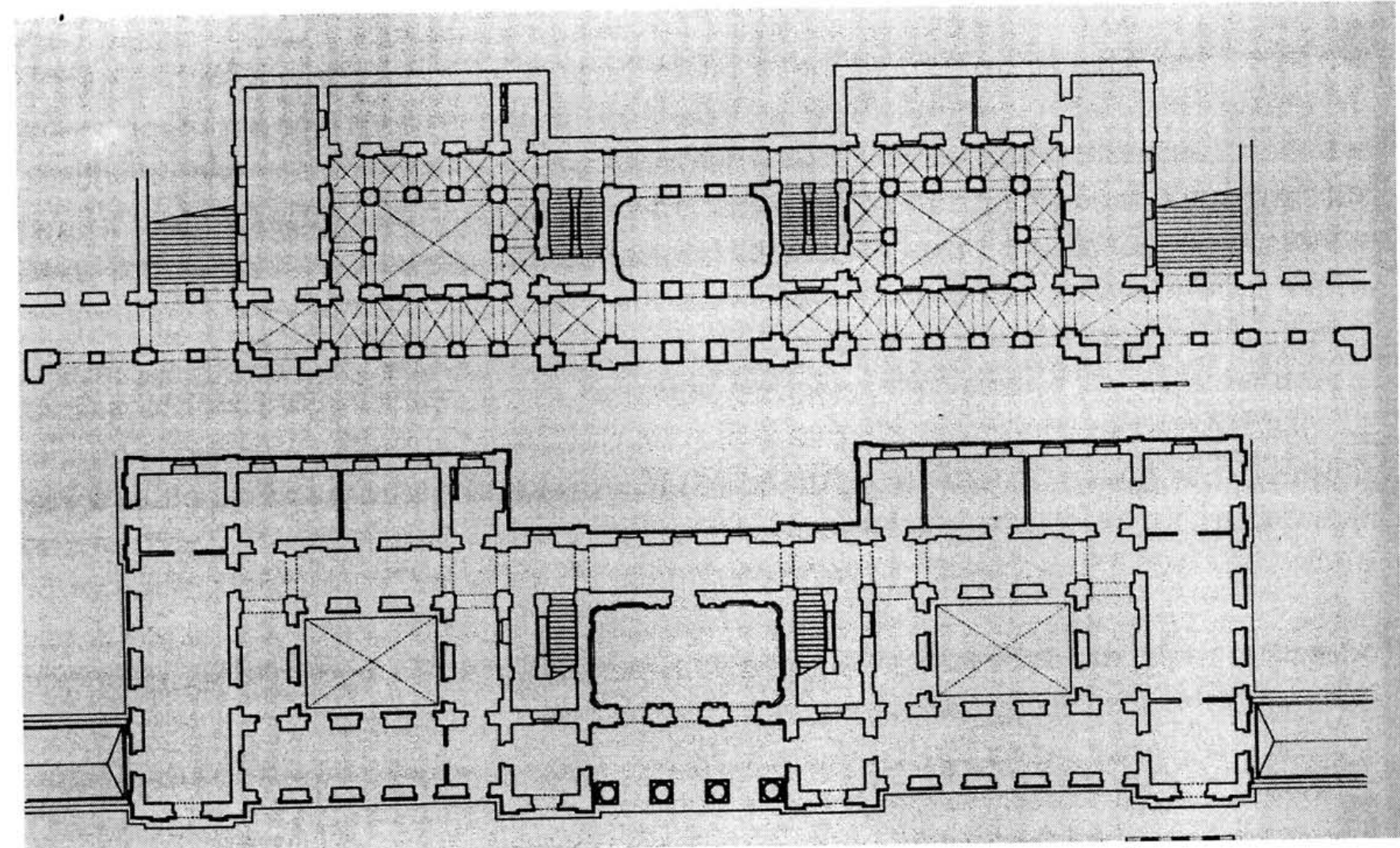

Figura 5. Proyecto de Casa Consistorial (F.D., 1861). Plantas baja y primera (Fuente: FERNÁNDEZ FERNÁNDEZ, X.: op. cit. p. 77). 
Guardia Municipal y el local del archivo. En la planta principal el espacio del vestíbulo inferior es ocupado por el salón de sesiones, ámbito más cuidado decorativamente por las pilastras corintias adosadas a sus muros sobre un alto zócalo, junto con los despachos del alcalde y secretario, sus respectivas oficinas y antesala, un depósito de libros, sala de conferencias para los regidores, guardarropa y en la parte izquierda tres locales para la Diputación: un salón de plenos, un despacho para su secretaría y un archivo. En la planta segunda se alojarían otras corporaciones locales como la Academia de Medicina, la Contaduría de Hipotecas o los Juzgados de Paz y de $1^{\mathrm{a}}$ instancia, además de salas para juicios verbales, comisiones ordinarias y extraordinarias, escribanos y porteros; en el ático estarían el resto de oficinas incluidas las de Estadística y Beneficencia local, depósito de planos y documentos, almacenes, habitación del jefe de la Guardia Municipal, guarda muebles...

En esa apretada distribución interior prácticamente ha desaparecido toda huella de los principios compositivos durandianos puesto que los condicionantes del terreno y la gran variedad de oficinas a albergar determinan ahora una organización más pragmática y adaptada a un programa de usos bien definido. También hay que tener en cuenta los años transcurridos, con la consiguiente experiencia constructiva acumulada, a pesar de lo cual como poso de aquella formación el arquitecto declarará en la memoria que a veces era preciso lograr «la elegancia y la belleza más que en la riqueza de los detalles, en la disposición conveniente de los espacios» ${ }^{23}$.

Al margen de lo reseñado el proyecto desarrolla una vocación urbanística ausente en el anterior al buscar conscientemente la armonización con los otros tres lados de la plaza proyectada, ocupados por un uniforme caserío también diseñado por Domínguez (Fig. 6). De ahí se derivaría la solución porticada para la planta baja, con dos tramos laterales que unirían el Ayuntamiento a las casas de las correspondientes esquinas ${ }^{24}$. Ahora bien, armonización no implica integración puesto que el arquitecto tenía bien claro que «en una plaza pública el edificio destinado a residencia del Municipio debía distinguirse de las habitaciones de los vecinos por su

${ }^{23}$ A.M.C. Obras Municipales. C-1013. «Proyecto de una casa de ayuntamiento para la capital». Doc. $\mathrm{N}^{\circ} 1$. Memoria descriptiva. Faustino Domínguez. 7-VII-1861.

${ }^{24}$ Aunque el resto de planos del proyecto se encuentran en el Archivo Municipal (Obras Municipales, C-1013), el alzado principal y su sección, publicados por Arturo Franco Taboada, han desaparecido del mismo.

"CUADERNOS DE ESTUDIOS GALlEGOS", Tomo XLII, Fascículo 107, Santiago 1995. 


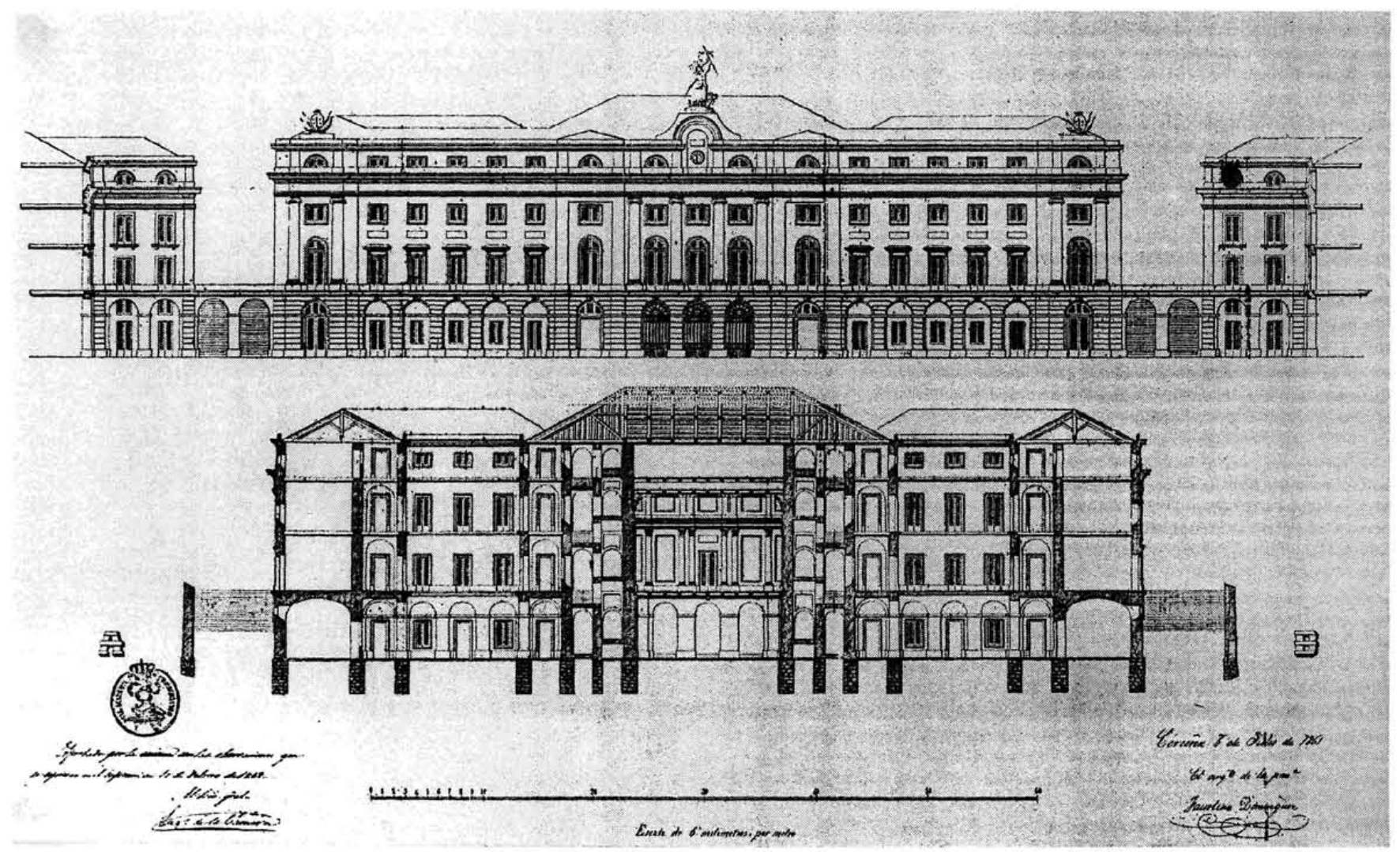

Figura 6. Proyecto de Casa Consistorial (F.D., 1861). Fachada principal y sección (Fuente: FRANCO TABOADA, A.: op. cit. p. 99). 
mayor altura y por la riqueza de su ornamentación $\rangle^{25}$. Aislando la Casa Consistorial de los tramos residenciales y dándole mayor altura en el nivel principal el edificio presidiría decididamente la nueva plaza, si bien resulta curioso comprobar hasta que punto se hace permeable a su espacio ya que la circulación por el tramo porticado podría continuarse por las dos galerías que rodean los patios interiores, circunstancia pensada para la reunión de público con ocasión de los sorteos de quintas o las elecciones.

En el alzado principal también puede apreciarse la misma simplificación ya señalada para el interior, alcanzándose el justo equilibrio en la disposición de órdenes y juego de dimensiones horizonales y verticales. El leve saliente del cuerpo central con su pórtico de columnas jónicas tetrástilas tiene su contrapunto en los pares de pilastras de los extremos, a la vez que ganan protagonismo los grandes ventanales del balcón central que ofrecen luz al salón de plenos. Unificando las tres partes de la fachada ahora surge un afortunado y movido ático en cuyo centro destaca el reloj y la estatua dedicada a María Pita y en los laterales los escudos de la ciudad ${ }^{26}$.

Por otra parte, la señalada transición hacia el eclecticismo encuentra además su fundamento en la preocupación del arquitecto para justificar la elección de un determinado estilo - el "greco-romano» -, a la hora de revestir un edificio que debía expresar su carácter político y representativo. Según dejó consignado en la memoria, para esta elección había tenido en cuenta que las columnas de la fachada debían «reunir la solidez necesaria para el peso que habian de soportar», siendo el orden jónico "por su carácter intermedio entre la delicadeza y la rigidez de la fuerza... el más a propósito para los edificios administrativos, y porque se presta mejor que los otros del mismo estilo a caracterizarlos y embellecerlos decorosamente».

El proyecto fue aprobado por Real Orden del 13 de Marzo de 1862 tras haber pasado los exámenes de la Academia de San Fernando, que hizo ligeras observaciones, y la Junta Consultiva de Policía Urbana del Ministerio de la Gobernación ${ }^{27}$. Lamentablemente el elevado presupuesto próximo

\footnotetext{
${ }^{25}$ Idem, ídem.

${ }^{26}$ Dentro de su sencillez, reconocida por el propio arquitecto, esta fachada comparte recursos como ese arco de remate sobre el reloj con otros edificios municipales como el Ayuntamiento de Gijón de Andrés Coello.

${ }^{27}$ Para dicha Junta el proyecto era «uno de los más completos y mejor estudiados» que habían pasado a su informe. A.M.C. Obras Municipales. C-1013. «Exp. relativo al proyecto de edificación de una nueva Casa Consistorial...».
} 
a los 3.500.000 de reales acabaría abortando su ejecución, lo que conduciría a que en 1879 su hijo Faustino Domínguez Coumes-Gay elaborara otra propuesta, luego también abandonada en favor del definitivo proyecto de Pedro Mariño ${ }^{28}$.

Llegamos así al último hito en la producción de Domínguez que nos habíamos marcado: el edificio para la Diputación Provincial de La Coruña proyectado en 1862. Los antecedentes de esta construcción son complejos puesto que es preciso remontarlos al proyecto inicial de José María Noya para el Teatro Principal (1838), donde se preveía que este recinto se acompañara con dos edificios laterales con una fonda, café y salones para bolsa de Comercio, bailes y otras habitaciones ${ }^{29}$. En el transcurso de las obras el ambicioso proyecto tuvo que se recortado por razones presupuestarias, eliminándose no sólo esos edificios laterales sino el mismo cuerpo de fachada hacia Riego de Agua, gracias a lo cual el teatro pudo inaugurarse en 1840.

Ocho años más tarde y con mejores circunstancias económicas se decidió construir el edificio que debía situarse en el lateral del teatro hacia la calle Agar para albergar una "casa-café» y una «casa de baños», con lo que vendría a completar al teatro con aquellas otras dependencias accesorias ya previstas en 1838. Los planos para este edificio, debidos otra vez a José María Noya, se remitieron a la Academia de San Fernando en Junio de 1848 e incluían tanto las obras ya efectuadas - el teatro - como aquellas otras partes cuya edificación aún no se había planteado - la fachada y el costado Este -, por lo que se trataría de los planos del proyecto original que, al parecer, nunca habían sido enviados para su aprobación. De este modo al obtener el visto bueno para el edificio lateral se buscaba implícitamente la aceptación de lo ya construido, hecho que no pasó desapercibido para la Academia que ordenó su corrección y posterior reenvío, algo que nunca tendría lugar ${ }^{30}$. Finalmente la dirección de las obras corrió a cargo de Pascual

\footnotetext{
${ }^{28}$ Este último aún conocería distintas soluciones y reelaboraciones entre 1897 y 1901 hasta que finalmente en 1917 se remató lo fundamental del actual Palacio Municipal. FERNANDEZ FERNANDEZ, X. : op. cit. (pp. 97 a 135).

${ }^{29}$ Empresa de un nuevo teatro y de dos edificios laterales en la ciudad de La Coruña. Imprenta de Iguereta, La Coruña, 1838. Más detalles en SANCHEZ GARCIA, J. A. : «José María Noya y el proyecto...»; IDEM : El Teatro Rosalía Castro. Vía Lactea ed., La Coruña, 1995.

${ }^{30}$ A.R.A.B.A.S.F. Informes de Arquitectura. Teatros (1788-1862). La Coruña. Leg. 1848. 20 de Junio.
}

"CUADERNOS DE ESTUdiOS GALLEGOS", Tomo XLII, Fascículo 107, Santiago 1995. 
Rosende, pero una vez terminado en 1850 fue adquirido por la Diputación Provincial para instalar sus oficinas y las del Gobernador Civil ${ }^{3 !}$.

Años después la Diputación se haría con el resto de terrenos y en 1862 encargaría a Faustino Domínguez cerrar el perímetro del teatro con el cuerpo de fachada a Riego de Agua y el otro edificio lateral hacia la calle Luchana. Ambos se destinarían para ampliar las dependencias del ente Provincial y el Gobierno Civil que ya se encontraban muy constreñidas de espacio $^{32}$. El proyecto fue aprobado por una Real Orden del 17 de Mayo de 1862, aunque previamente debió concurrir ante el preceptivo examen de la Academia de San Fernando. En el mismo se señalaban algunos rasgos a mejorar por el arquitecto como hacer más ancho el resalto del cuerpo central en la fachada, dar más uniformidad a sus ventanas, dotarlas a todas con idéntico guardapolvo, o rasgar las ventanas apaisadas del segundo piso en la fachada principal ${ }^{33}$. Las obras del definitivo Palacio de la Diputación se terminarían en 1865 , con lo que aún sin responder al proyecto original quedó concluida la problemática manzana del «Teatro Rosalía» con una forzada convivencia entre distintos usos e instituciones que aún hoy en día se mantiene $e^{34}$.

${ }^{31}$ FAGINAS ARCUAZ, R.: Guia-Indicador de La Coruña y de Galicia para 1890 91. Imp. y Est. de Vicente Abad, La Coruña, 1890 (p. 138). Por lo tanto Pascual Rosende nunca formó los planos para este edificio como afirma FERNANDEZ FERNANDEZ, X. : op. cit. (p. 97).

${ }^{32}$ En Octubre la Diputación «con presencia de proyectos y planos formados para las obras necesarias en esta misma casa a fin de completar la edificación de su segundo cuerpo con obgeto de dar cavida en él a las dependencias provinciales... determinó por unanimidad verificar las citadas obras». Archivo de la Diputación Provincial de La Coruña. Libro de Actas, años 1857-1864. Año 1862, sesión del 20 de Octubre.

${ }^{33}$ Unas indicaciones últimas se referían al entorno ya que «la importancia de este múltiple edificio exige que en el recinto del mismo se estudie alguna reforma de las alineaciones aislándole por medio de la rectificación y ensanche de las calles que le rodean y forman a su frente una pequeña plazuela de desahogo». A.R.A.B.A.S.F. Actas de la Sección de Arquitectura, Libro de 1860 a 1888. Junta del 2-V-1862, fol. 40. También A.M.C. Bienes Municipales. «Expediente sobre cesión a la provincia de la casa número 33 de la calle de Luchana de esta capital perteneciente al Exmo. Ayuntamiento». Solicitud de cesión de dicha casa por parte del Gobernador a 17 de Diciembre. Sin folio.

${ }^{34}$ En nuestros días la sede de la Diputación se trasladaría al edificio del Teatro Colón, destinándose la crujía Este y el cuerpo de fachada a Riego de Agua para alojar la Biblioteca Provincial, mientras que por el lado Oeste se instalaron las oficinas de arquitectura y la unidad de informática.

"CUADERNOS DE ESTUDIOS GALLEGOS", Tomo XLI1, Fascículo 107, Santiago 1995. 

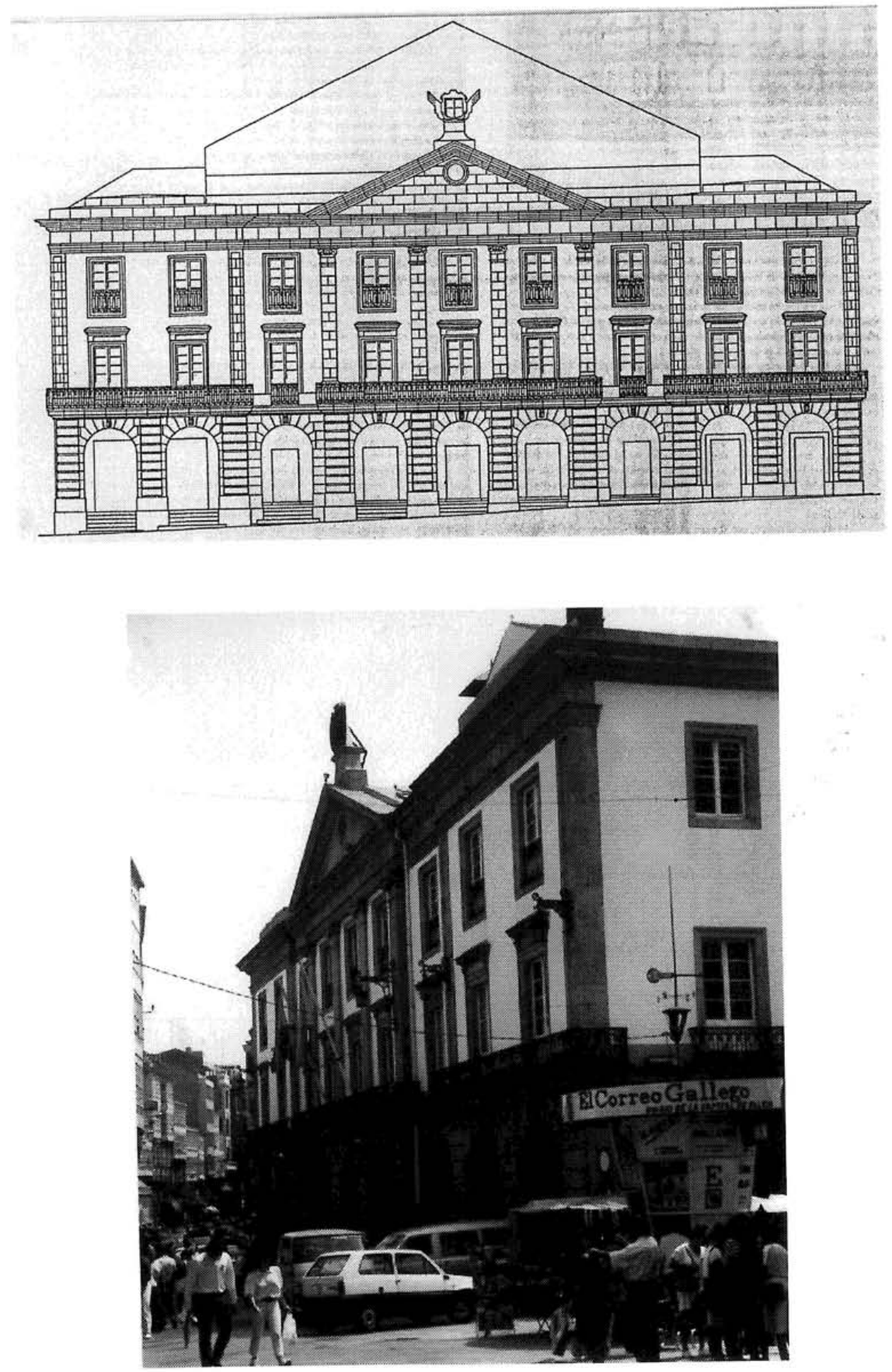

Figura 7. Palacio de la Diputación Provincial (F.D., 1862). Fachada principal. 
De este edificio lo más interesante es la solución de fachada puesto que en la distribución interior pocos recursos pudo desplegar Domínguez dado el estrecho y difícil espacio con que contaba ${ }^{35}$. En esa fachada los elementos clásicos se han convertido en algo accesorio, añadido, con una mera funcion emblemática dentro de un conjunto que ya se encuentra a gran distancia de aquel neoclasicismo de formación ${ }^{36}$. Ahora su autor confirma su evolución hacia el ámbito de lo ecléctico, si bien aferrándose al sustrato clasicista que hemos visto permanecer vigente en toda su trayectoria (Fig. 7).

La ordenación del frontis basada en potentes columnas se sustituye por unas pilastras, siempre jónicas, que configuran la tradicional solución tetrástila, en esta ocasión sólo en el centro y coronada por un frontón triangular. Tanto ese cuerpo central como los laterales, enmarcados por pilastras, vuelven a adelantarse del plano de fachada quebrando el entablamento y repitiendo otro de los recursos favoritos en la arquitectura de Domínguez. También se mantiene el soportal inferior, continuando el tramo ya iniciado en 1850, con el tratamiento almohadillado constante en los tres proyectos examinados. Pedro Navascués ha señalado que este esquema de composición de fachada es muy típico tanto de los edificios teatrales como de las diputaciones, lo cual nos lleva a preguntarnos por la intención significante de Faustino Domínguez en este caso concreto. A la vista de los argumentos expuestos en el anterior proyecto y la reiteración de elementos como el orden jónico, pensamos que el frente añadido al teatro es planteado exclusivamente como el ropaje para un edificio político, obviando el otro recinto

\footnotetext{
${ }^{35}$ En la planta baja se situaban una amplia escalera, salón para quintas y reconocimientos, archivo y oficinas; en la principal la crujía frontal acogía el despacho del presidente y la bibilioteca, la occidental el nuevo salón de sesiones, con su propio acceso, y la oriental la secretaría, depositaría, contaduría, salón de la comisión permanente y despachos; en el piso segundo las habitaciones particulares del gobernador se añadían a las oficinas de la Junta provincial de beneficencia y sanidad, sección de fomento, negociado de presupuestos y otras oficinas. FAGINAS ARCUAZ, R. : op. cit. (pp. 138 y 139).

${ }^{36}$ Además de las referencias ya citadas véanse también NAVASCUES PALACIO, P.: La arquitectura gallega del siglo XIX... (pp. 13 a 15); SORALUCE BLOND, J. R. : «Teatro Rosalía de Castro. La Coruña» en Arquitectura Teatral en España (VV.AA.). Dirección General de Arquitectura y Vivienda. MOPU, Madrid, 1985 (pp. 132 a 135); y MARTINEZ SUAREZ, X.L.: As galerías da Mariña. A Coruña 1869-1884. COAG, A Coruña, 1987 (pp. 38 a 41).
}

"CUADERNOS DE ESTUDIOS GALLEGOS", Tomo XLII, Fascículo 107, Santiago 1995. 
inscrito tras él. Además, la austeridad y la planitud de sus elementos compositivos, sin olvidar la destacada presencia de los balcones corridos para alocuciones públicas o el escudo de armas en hierro forjado que corona el frontón superior, imprimen un carácter muy similar al de otras diputaciones, como por ejemplo la de Burgos (Fig. 8) ${ }^{37}$.

En suma, estos ejemplos en la arquitectura de Faustino Domínguez lo sitúan como una figura de primer orden en el contexto de disolución del clasicismo durante el tercio central del XIX al desarrollar una opción conservadora que transmutó y adaptó sus principios esenciales a unas construcciones dentro ya de la corriente ecléctica imperante. Por esta razón su arquitectura de madurez obligatoriamente ha de encuadrarse en un eclecticismo clasicista, sobrio y desornamentado, paradójicamente más cercano al academicismo del siglo XVIII que al neoclasicismo de su formación.

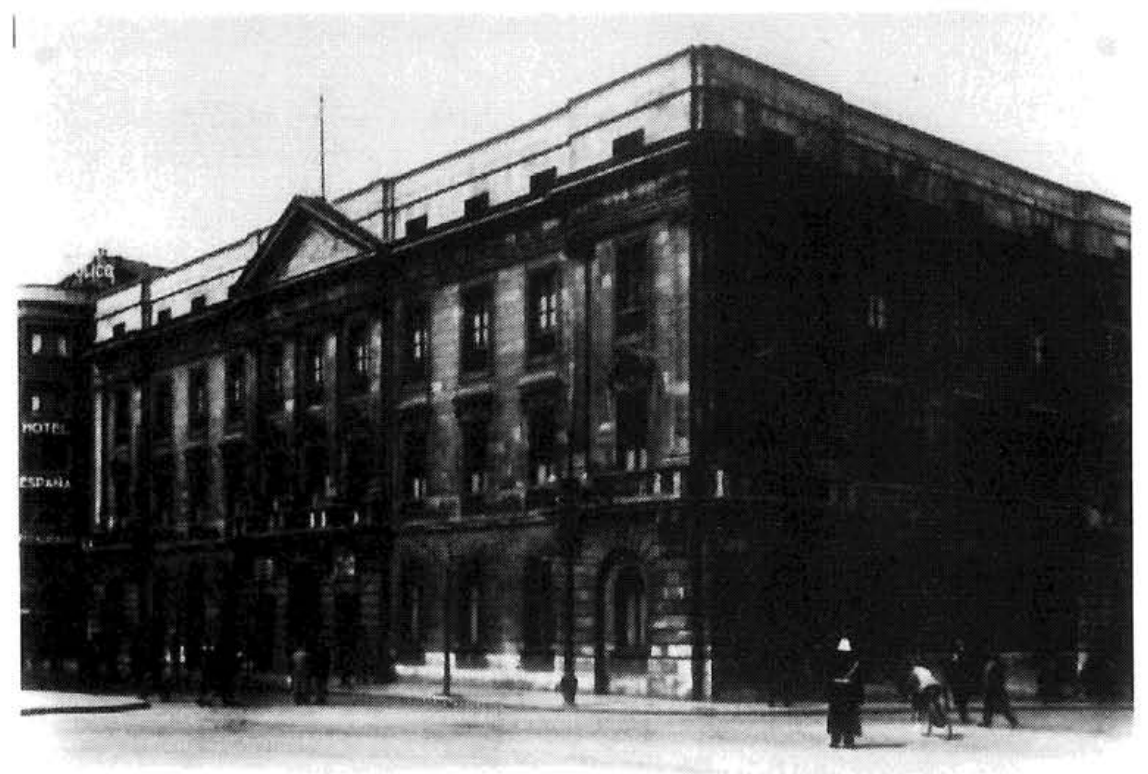

Figura 8. Diputación Provincial de Burgos (1871). Fachada principal (Fuente: IGLESIAS ROUCO, L.S.: op. cit. p. 138).

${ }^{37}$ IGLESIAS ROUCO, L. S.: Burgos en el siglo XIX. Arquitectura y urbanismo (1813-1900). Univ. de Valladolid, 1979 (pp. 129 a 138).

"CUADERNOS DE ESTUDIOS GALLEGOS", Tomo XLII, Fascículo 107, Santiago 1995. 